\title{
ANÁLISIS DE LOS DAÑOS EN VIVIENDAS Y EDIFICIOS COMERCIALES DURANTE LA OCURRENCIA DEL SISMO DEL 19 DE SEPTIEMBRE DE 2017
}

\author{
Luis Manuel Buendía Sánchez ${ }^{(1)}$ y Eduardo Reinoso Angulo ${ }^{(2)}$
}

\begin{abstract}
RESUMEN
Se presenta un análisis de los daños en estructuras de los estados de México, Morelos, Puebla y la Ciudad de México durante la ocurrencia del sismo del 19 de septiembre de 2017, mediante datos recolectados en diversas fuentes como reportes, visitas técnicas y redes sociales, entre otros. Con los datos recabados fue posible geo-localizar cada estructura a nivel predio e identificar las características de cada inmueble tales como el número de pisos y el sistema estructural, además de posibles agravantes de los daños presentados tales como irregularidades geométricas y daños previos, entre otros. Se presenta un análisis estadístico de estos factores con la finalidad de identificar la vulnerabilidad y poder encontrar tendencias para estimar el riesgo.
\end{abstract}

Palabras Clave: septiembre de 2017; daños en estructuras; estadísticas de daños; bases de datos; sistema de información geográfica

\section{ANALYSIS OF DAMAGES IN HOUSING AND COMMERCIAL BUILDINGS DURING THE OCCURRENCE OF THE EARTHQUAKE OF SEPTEMBER 19, 2017}

\begin{abstract}
An analysis of the structural damage presented during the September 19, 2017 earthquake in Puebla, Morelos, state of Mexico and Mexico City is presented. The analysis has been carried out by studying different collected data from several sources (such as technical reports, technical visits and social networks, among others). By using the collected data, it was possible to create databases associated to each different city and, subsequently, through a detailed analysis it was possible to develop a geographic information system (GIS), where additional data such as structural characteristics and performance modifiers were included. Statistical analysis in terms of many parameters related with structural damage are presented.
\end{abstract}

Keywords: Earthquake, September 2017; structural damage; damage statistics; damage database; GIS

\footnotetext{
Artículo recibido el 16 de julio de 2018 y aprobado para su publicación el 23 de octubre de 2019. Se aceptarán comentarios y/o discusiones hasta cinco meses después de su publicación.

(1) ERN Evaluación de Riesgos Naturales SA de CV. Vito Alessio Robles 179, Col. Hda, Guadalupe Chimalistac. Del. Álvaro Obregón. 01050, Ciudad de México.1buendias@ern.com.mx

(2) Instituto de Ingeniería UNAM, Torre de Ingeniería, Universidad Nacional Autónoma de México, 04510, Ciudad de México. EReinosoA@iingen.unam.mx
} 


\section{INTRODUCCIÓN}

El 19 de septiembre de 2017, ocurrió un sismo de magnitud 7.1 en la zona de Axochiapan, Puebla, afectando a los estados de Puebla, Morelos, Estado de México, Guerrero, Oaxaca, Veracruz, Michoacán, Hidalgo y la CDMX. Las aceleraciones espectrales registradas en ciertas zonas de la CDMX, especialmente en la zona de periodos cortos de la zona lago, fueron bastante altas, llegando incluso a superar valores de $1.0 \mathrm{~g}$. La ocurrencia de este sismo dejó como consecuencia varias estructuras dañadas y colapsadas además de centenas de víctimas fatales y miles de damnificados, siendo así uno de los sismos más desastrosos que se ha registrado en la historia moderna de México.

Inmediatamente después de la ocurrencia de este sismo, voluntarios y diversas instituciones tanto nacionales como internacionales realizaron recorridos en las zonas dañadas con la finalidad de poder evaluar preliminarmente los efectos de este sismo, entre ellas la Facultad de Ingeniería y la Facultad de Arquitectura de la UNAM, el Colegio de Ingenieros Civiles de México (CICM), la Sociedad Mexicana de Ingeniería Estructural (SMIE), la Sociedad Mexicana de Ingeniería Sísmica (SMIS), la Sociedad Mexicana de Ingeniería Geotécnica (SMIG), el Instituto para la Seguridad de la Construcciones del Gobierno de la Ciudad de México e instituciones internacionales tales como la Geotechnical Extreme Events Reconnaissance Association (GEER), el Earthquake Engineering Research Institute (EERI) y la Universidad de Stanford, California.

Lamentablemente, al igual que en sismos pasados, no se tiene aún un conteo detallado de todas las estructuras que resultaron dañadas, pero gracias a las tecnologías de información y a la cooperación de la población en general, además de instituciones gubernamentales y civiles, la información recabada durante la emergencia y en días posteriores ha sido significativamente mayor y de mucho mejor calidad que en sismos pasados. Sin embargo, no es posible tomar esta información como verdadera debido a la enorme cantidad de noticias erróneas o falsas que pudieran surgir durante este desborde de intercambio de información, o que simplemente por la emergencia la información no se recabó con la calidad necesaria para utilizarla en un análisis estadístico, por lo que es necesario realizar un análisis detallado antes de poder hacer uso de la misma. Este gran esfuerzo se vio reflejado en la realización de distintos mapas preliminares de daños, los cuales fueron de ayuda en la emergencia para localizar estructuras colapsadas tales como los de Google (2017) el cual se iba alimentando por usuarios durante la emergencia, proporcionando ubicación de estructuras seriamente dañadas o colapsadas e información adicional como centros de atención a la emergencia y centros de acopio, entre algunas otras; al ser un mapa cuya fuente de información eran los mismos usuarios tenía mucha información repetida e imprecisa. Posteriormente hubo mapas más confiables como el de Verificado 19S (2017) que, al igual que el anterior, proporcionaba datos sobre daños, albergues y centros de acopio. Existen también mapas más refinados donde muchos de los datos ya han sido depurados, tal es el caso como los mapas que presenta el CICM, la SMIE y la SMIG, realizados con información de las brigadas de ingenieros que realizaron recorridos en las zonas dañadas por el sismo, proporcionando información más detallada en términos de ingeniería estructural sobre los daños observados (CICM-SMIE, 2017) Por su parte el Gobierno de la Ciudad de México a través del portal Plataforma CDMX (Gobierno de la Ciudad de México, 2017) presenta un mapa con el estado actual de las construcciones con un dictamen verificado del estado de daño que poseen; dicho portal incluye además información sobre donativos recibidos, recursos asignados y acciones realizadas. Posteriormente se realizaron diversos reportes preliminares de daños (GEER, 2017; Galvis et al., 2017; Rodríguez, 2017; Díaz et al., 2017) y seminarios (EERI, 2017; EERI, 2018), donde toda la información sobre los daños va siendo actualizada.

A partir del análisis de las diversas bases de datos, se logró crear una nueva base unificada con información georreferenciada y con las características estructurales de cada uno de los registros que la componen. Esta base de datos tiene como finalidad realizar un análisis estadístico de los daños, estudiar los diferentes efectos, incluyendo la intensidad de movimiento, que pudieron haberlos causado. 


\section{BASE DE DATOS DE ESTRUCTURAS DAÑADAS}

Se realizó una búsqueda exhaustiva de evidencias de los daños dejados por el sismo consultando bases de datos, reportes periodísticos, medios electrónicos, visitas de campo y redes sociales. Se analizaron todos los medios posibles a fin de discriminar aquellos donde la información no fuera precisa o presentara inconsistencias, para así, poder obtener el mayor universo posible de casos sustentado con registros fotográficos. Posteriormente usando bases de datos tales como, las del CICM-SMIE, Google, EERI, y Plataforma CDMX, fue posible incluir edificios que no habían sido registrados en el primer muestreo de la base de datos realizada.

Se localizaron todas las edificaciones con ayuda de GoogleEarth ${ }^{\circledR}$, Street View ${ }^{\circledR}$ y Google Maps ${ }^{\circledR}$, para posteriormente recabar el domicilio de cada edificación. Cada estructura reportada en las bases de datos citadas se vinculó con bases de datos existentes de direcciones de la CDMX, logrando con ello ubicarlas a nivel lote $\mathrm{y}$, en algunos casos, obtener información adicional como el año de construcción de la estructura que no estaba reportada en ninguna de las bases de daños. Esta precisión en la ubicación es necesaria para contar con mapas confiables y realistas, además de que se relacionarán los daños con las estimaciones georreferenciadas de la intensidad medida en términos de aceleraciones espectrales. En la figura 1 se muestra de manera ilustrativa la delimitación de un predio utilizando el catastro de la CDMX.

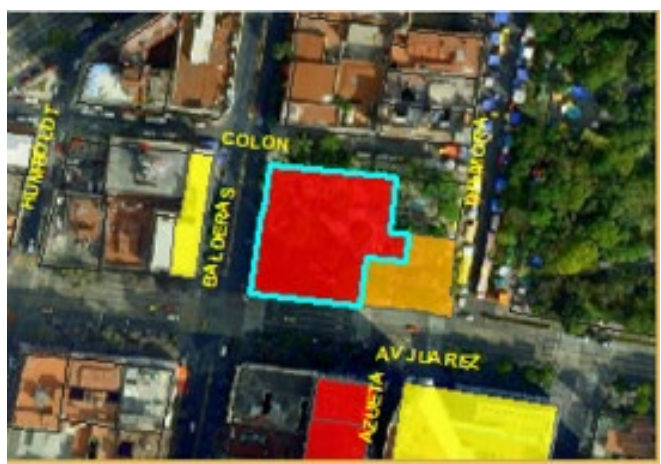

Figura 1. Utilización del catastro de la CDMX para relacionar las bases de datos de daños logrando identificar las estructuras a nivel lote

Para poder diferenciar los diferentes niveles de daño en cada estructura de la base de datos, en este estudio se propone una caracterización de estados de daños que sea fácilmente identificable y diferenciable, y que, a su vez, permita diferenciar el tipo de estructuración y su respuesta ante sismos. Dicha caracterización está basada en una segregación que separa los tipos estructurales antiguos y sin ingeniería, de tipos estructurales modernos que son comúnmente usados para la edificación de estructuras. En la tabla 1 se presenta la caracterización de daño propuesta.

Para la asignación de los estados de daño previamente mostrados a cada una de las estructuras de las base de datos creada, se utilizaron en primera instancia todas las fotografías disponibles de los daños presentados. Posteriormente, para algunas estructuras fue posible cotejar la información con reportes de visitas técnicas y otras bases de datos tales como las del CICM-SMIE, EERI, Plataforma CDMX. Con esto fue posible crear un banco de imágenes del antes y después del sismo con la finalidad de, por un lado, tener referencias de las caractersiticas de la estructura antes de la ocurrencia del sismo y por otro, de los efectos que dejó su ocurrencia. En la figura 2 se muestra un ejemplo de las imágenes recolectadas sobre un mapa que muestra la localización de cada edificio al cual corresponden. 
Tabla 1. Caracterización de daño propuesto

\begin{tabular}{|c|c|c|c|}
\hline $\begin{array}{l}\text { Caracterización de } \\
\text { daño }\end{array}$ & $\begin{array}{l}\text { Estructuras con } \\
\text { ingeniería }\end{array}$ & Descripción & Simbología \\
\hline Daño en bardas & $\times$ & $\begin{array}{l}\text { Daño en bardas perimetrales o de colindancia en donde la falla } \\
\text { es por movimiento fuera de plano }\end{array}$ & \\
\hline Estructuras antiguas & $x$ & $\begin{array}{l}\text { Estructuras históricas (iglesias, conventos) construidas antes del } \\
\text { siglo XX }\end{array}$ & \\
\hline Estructuras débiles & $x$ & $\begin{array}{l}\text { Estructuras hechas de materiales pobres en resistencia tales } \\
\text { como adobe o mampostería sin confinar, o estructuras sin } \\
\text { ingeniería de mala calidad }\end{array}$ & \\
\hline $\begin{array}{l}\text { Grietas en acabados } \\
\text { y elementos no } \\
\text { estructurales }\end{array}$ & $\sqrt{ }$ & $\begin{array}{l}\text { Estructuras con ingeniería que presentan daños menores en } \\
\text { muros no estructurales, acabados, recubrimientos, instalaciones } \\
\text { y vidrios que no afectan la integridad de la estructura }\end{array}$ & 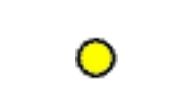 \\
\hline $\begin{array}{l}\text { Grietas pequeñas en } \\
\text { muros trabes o } \\
\text { columnas }\end{array}$ & $\sqrt{ }$ & $\begin{array}{l}\text { Además de los daños descritos en el punto anterior, se observan } \\
\text { grietas en elementos estructurales que evidencian daño } \\
\text { estructural }\end{array}$ & \\
\hline $\begin{array}{l}\text { Grietas importantes } \\
\text { en muros trabes o } \\
\text { columnas }\end{array}$ & $\sqrt{ }$ & $\begin{array}{l}\text { Además de los daños descritos en el punto anterior, se observan } \\
\text { grietas mayores en elementos estructurales, así como } \\
\text { deformaciones importantes y exposición del acero de refuerzo. } \\
\text { Este daño compromete la estabilidad de la estructura. }\end{array}$ & \\
\hline $\begin{array}{l}\text { Colapso de pisos } \\
\text { superiores }\end{array}$ & $\sqrt{ }$ & Colapso parcial de una parte superior de la estructura & \\
\hline Colapso & $\sqrt{ }$ & $\begin{array}{l}\text { La estructura colapsó en su totalidad; se incluye aquí el caso de } \\
\text { colapso de la planta baja }\end{array}$ & \\
\hline
\end{tabular}

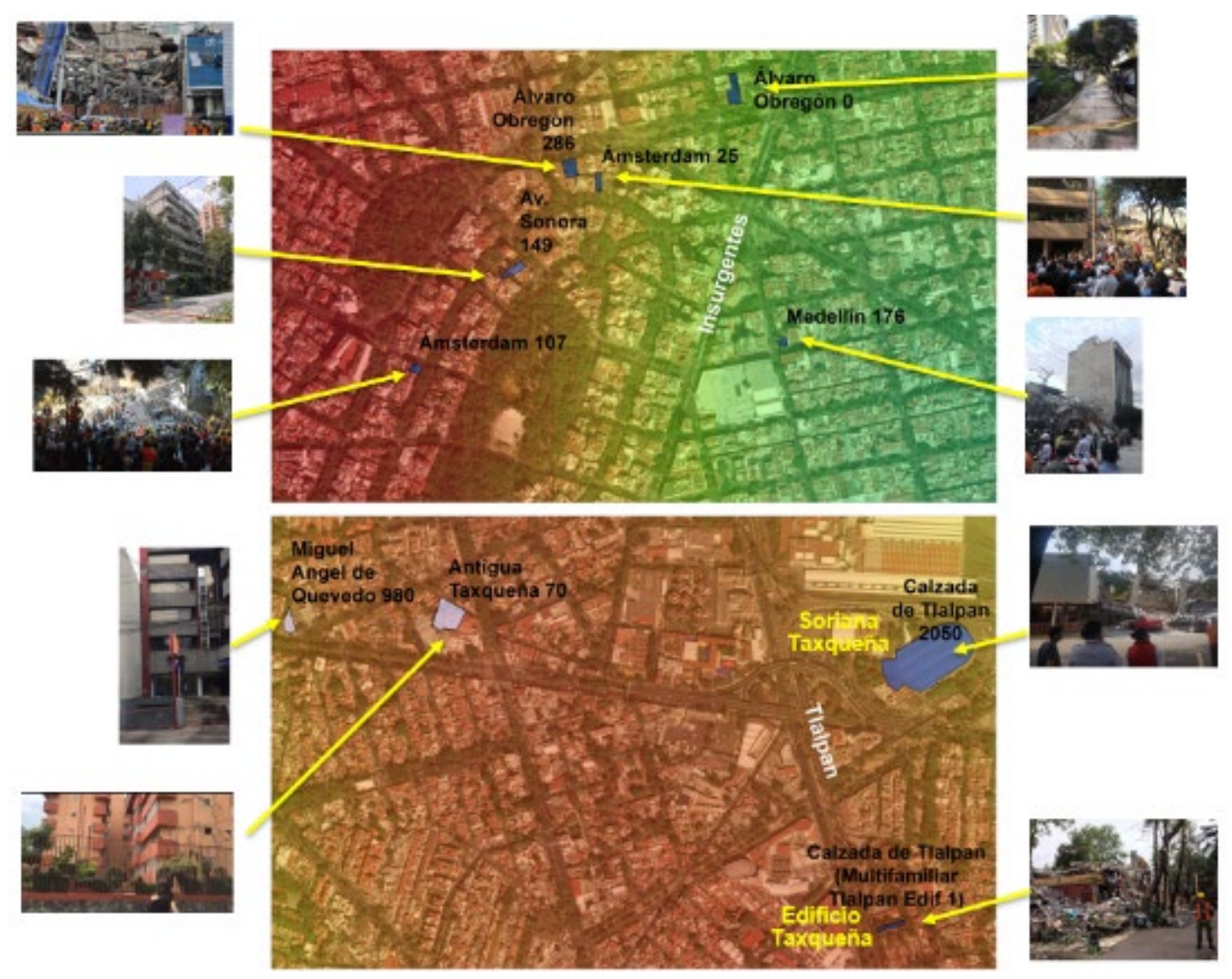

Figura 2. Banco de datos de imágenes, videos, testimonios y referencias geográficas de los daños 
La base de datos que contiene la evidencia de los daños registrados se vinculó a un archivo vectorial de polígonos que representan la lotificación de cada edificación. Con ello se logró obtener de manera exacta su ubicación geográfica, lo cual es muy importante ya que uno de los análisis consistió en relacionar los datos del suelo, la dinámica de las estructuras y el tipo de daño. Los trabajos anteriores se realizaron utilizando las herramientas de Sistemas de Información Geográfica SIG, lo cual es ampliamente recomendable para el manejo de la información espacial, su análisis, la emisión de los reportes preliminares y la creación de la estadística de daños.

El conjunto de la información geográfica que contiene la evidencia de los daños se integró a un sistema de visualización (ERN, 2018) que contiene los daños registrados durante los sismos del 28 de julio de 1957, 14 de marzo de 1979 y ambos del 19 de septiembre (1985 y 2017). Este visualizador es un sistema dinámico, interactivo e intuitivo que contiene las herramientas necesarias para la búsqueda de las edificaciones, acercamiento zoom y paneo para el desplazamiento en el mapa, mapas auxiliares de localización de calles y satélite $\left(\right.$ GoogleEarth $\left.{ }^{\circledR}\right)$, daños registrados de acuerdo al sismo histórico, nivel de daños, envío de comentarios y sugerencias y reporte de nuevos daños. En la figura 3 se presenta una vista general de la interfaz del visualizador de daños.

a)

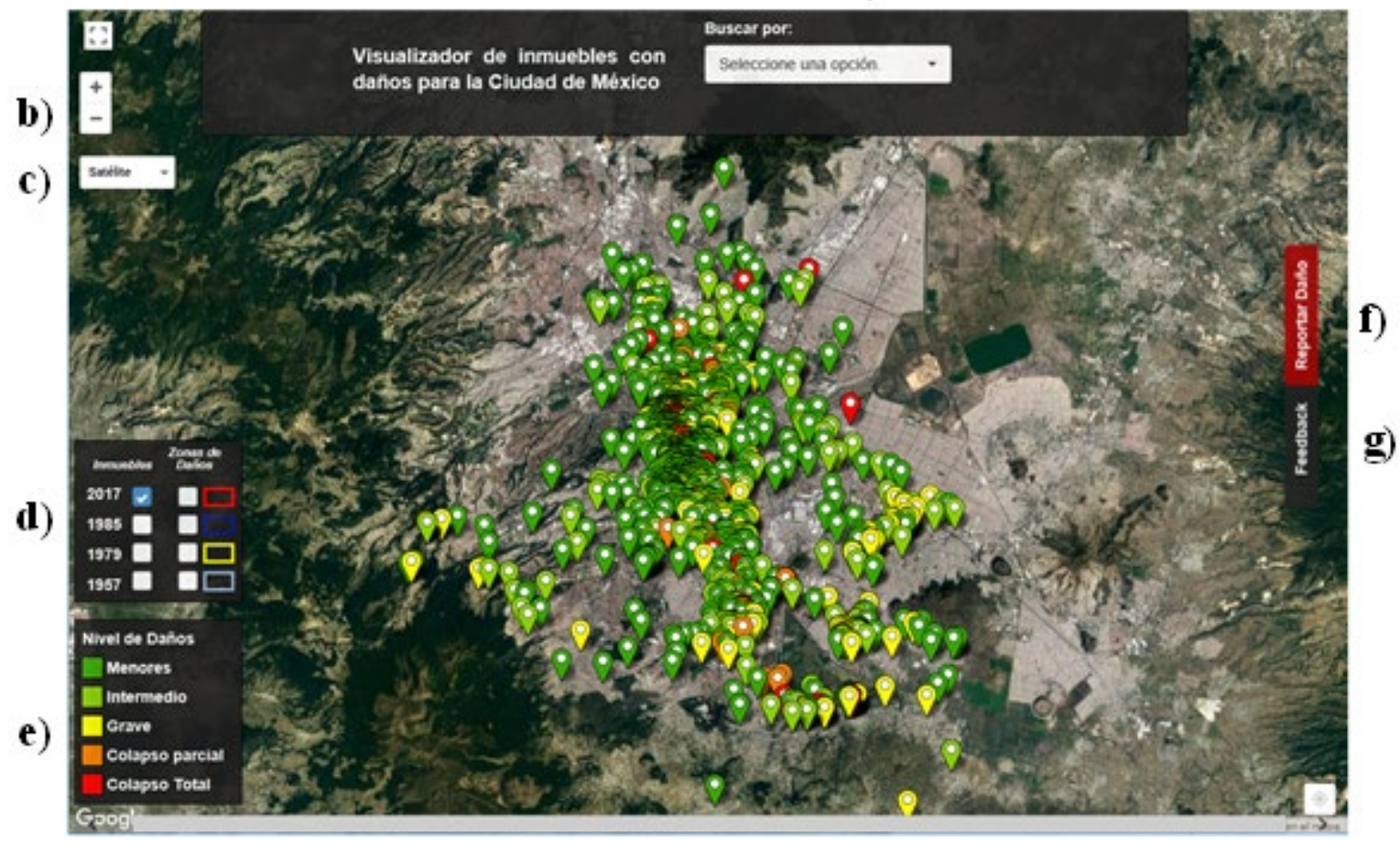

Figura 3. Interfaz del visualizador de daños por sismos en inmuebles de la CDMX. Contiene herramienta de interacción y consulta: a) búsqueda de edificaciones dañadas, b) acercamiento y paneo, c) mapas auxiliares de localización espacial, d) lista de sismos históricos, e) nivel de daño, f) reporte de nuevos daños y g) envío de comentarios y sugerencias

La herramienta de búsqueda de estructuras con daños acepta diferentes parámetros o atributos que identifican al inmueble como: calle, colonia, delegación, tipo de daño, nombre del edificio o uso. El sistema automáticamente direccionará a la edificación buscada. En la figura 4 se muestra el sistema de búsqueda y filtrado de información. 


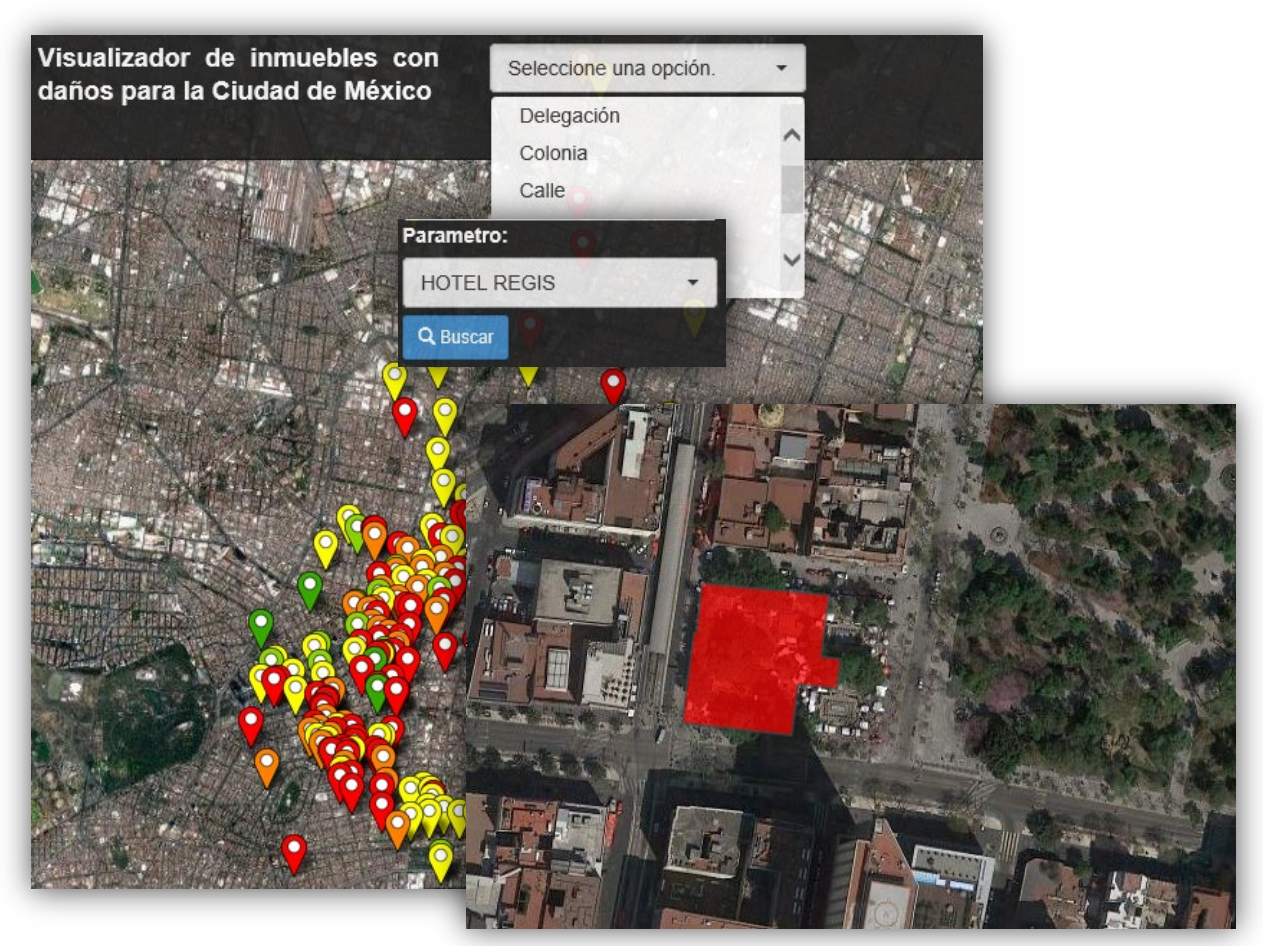

Figura 4. Herramienta de búsqueda de edificaciones dañadas, la consulta se realiza mediante los diferentes parámetros o atributos que identifican al inmueble, el sistema direcciona de manera automática a la estructura consultada daños.

En la figura 5 se presenta la ficha general de información asociada a cada registro del visualizador de

A continuación, se presenta una descripción general de cada parte de la ficha general de información mostrada en la figura 5 .

- Información general: incluye el nivel de daño y el sismo que lo causó

- Antes del sismo: información fotográfica previa al evento, los parámetros que identifican al inmueble y sus características estructurales

- Lo que pasó en el sismo: fotografías de los daños, listado de los agravantes que ocasionaron los daños, periodo del suelo y aceleración estimada en ese sitio

- Situación actual: fotografías y descripción de lo que existe actualmente en el sitio.

\begin{abstract}
ANÁLISIS DE DAÑOS
Actualmente se tiene una base de datos recabada con daños en los estados de Morelos, México, Puebla y la Ciudad de México. Sin embargo, al momento de la realización de este artículo, los daños presentados en los estados de Puebla, México y la Ciudad de México son los que se encuentran analizados en su totalidad con el nivel de detalle necesario para la realización de este artículo, por lo que se espera incluirlos en un futuro.
\end{abstract}




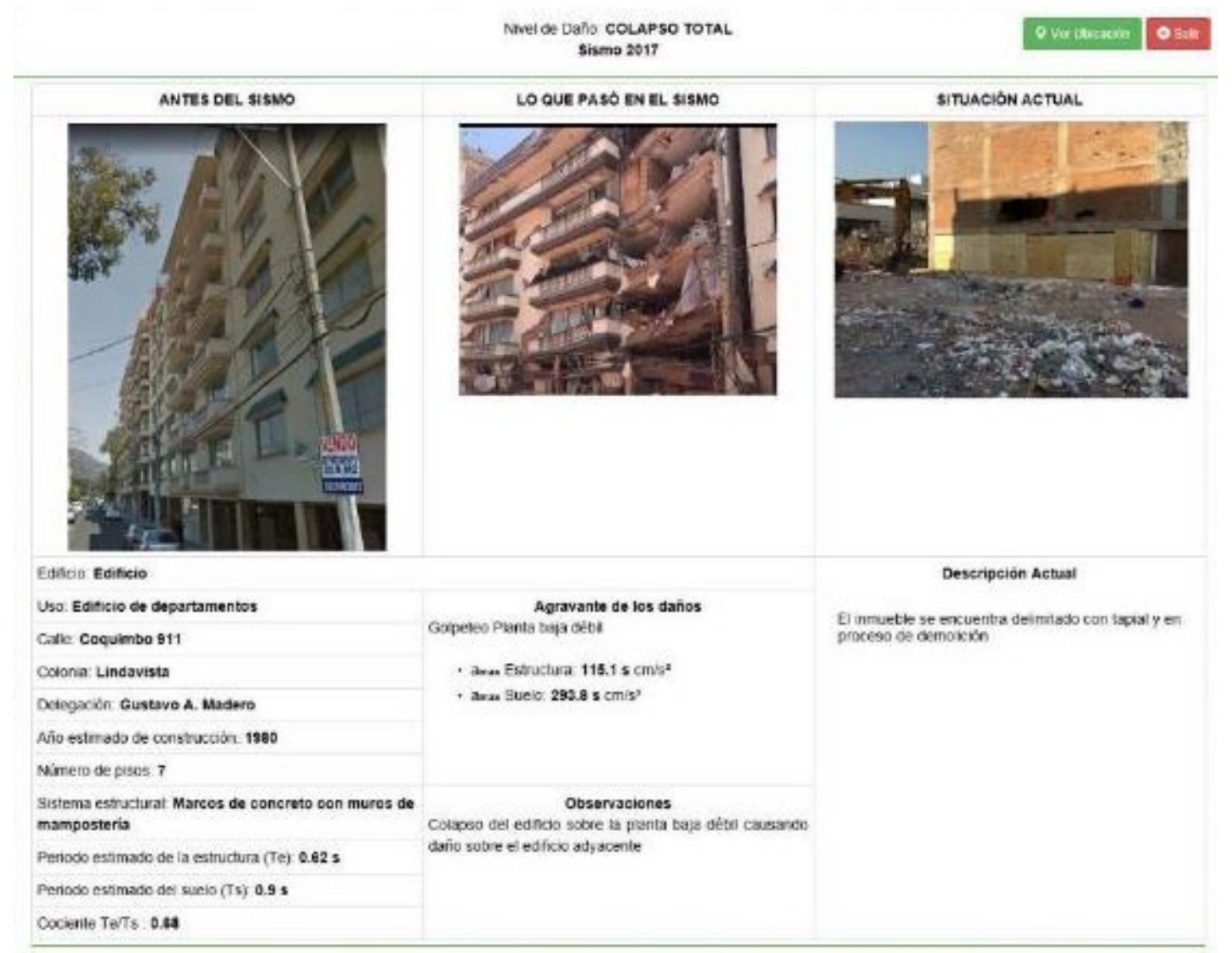

Figura 5. Visualización de la ficha general de información de cada edificio

En la figura 6 se presenta un mapa de aceleración del suelo ( $P G A$ por sus siglas en inglés), obtenido mediante el uso del programa CRISIS (Ordaz et al., 2017). Se puede observar que los valores de intensidad presentados corresponden con los estimados por el Instituto de Ingeniería de la UNAM (IINGEN), en la misma figura además se presentan la totalidad de los edificios con daños contenidos en la base de datos recabada. En la misma figura se puede observar que en la zona del epicentro (marcador de estrella) se alcanzó una intensidad de al menos $250 \mathrm{~cm} / \mathrm{s}^{2}$, disminuyendo progresivamente y alcanzado en algunas zonas del Estado de México, una intensidad de alrededor de $100 \mathrm{~cm} / \mathrm{s}^{2}$. También se presentan la localización de los edificios dañados, los cuales están representados como marcadores circulares, en los cuales cada color está asociado a la caracterización de daño presentada en la tabla 1. Se puede observar que en el Estado de Puebla se presentaron daños inclusive fuera de la zona de altas intensidades del sismo, existiendo incluso un colapso. De la misma manera, en el Estado de México se presentaron daños en zonas con intensidades de $50 \mathrm{~cm} / \mathrm{s}^{2}$. El estado de Morelos también resultó seriamente afectado presentando un gran número de estructuras dañadas. Se puede observar que para el caso de la Ciudad de México existe una gran concentración de los daños de Norte a Sur-este, presentando una gran cantidad de colapsos en la zona centro, en las delegaciones Cuauhtémoc, Benito Juárez y Coyoacán, lo cual corresponde a la zona de terreno blando. Se puede observar también que existieron daños en la zona de terreno firme en las delegaciones Cuajimalpa Álvaro Obregón y La Magdalena Contreras, sin embargo, la mayoría de estos daños corresponden a estructuras sin ingeniería. 


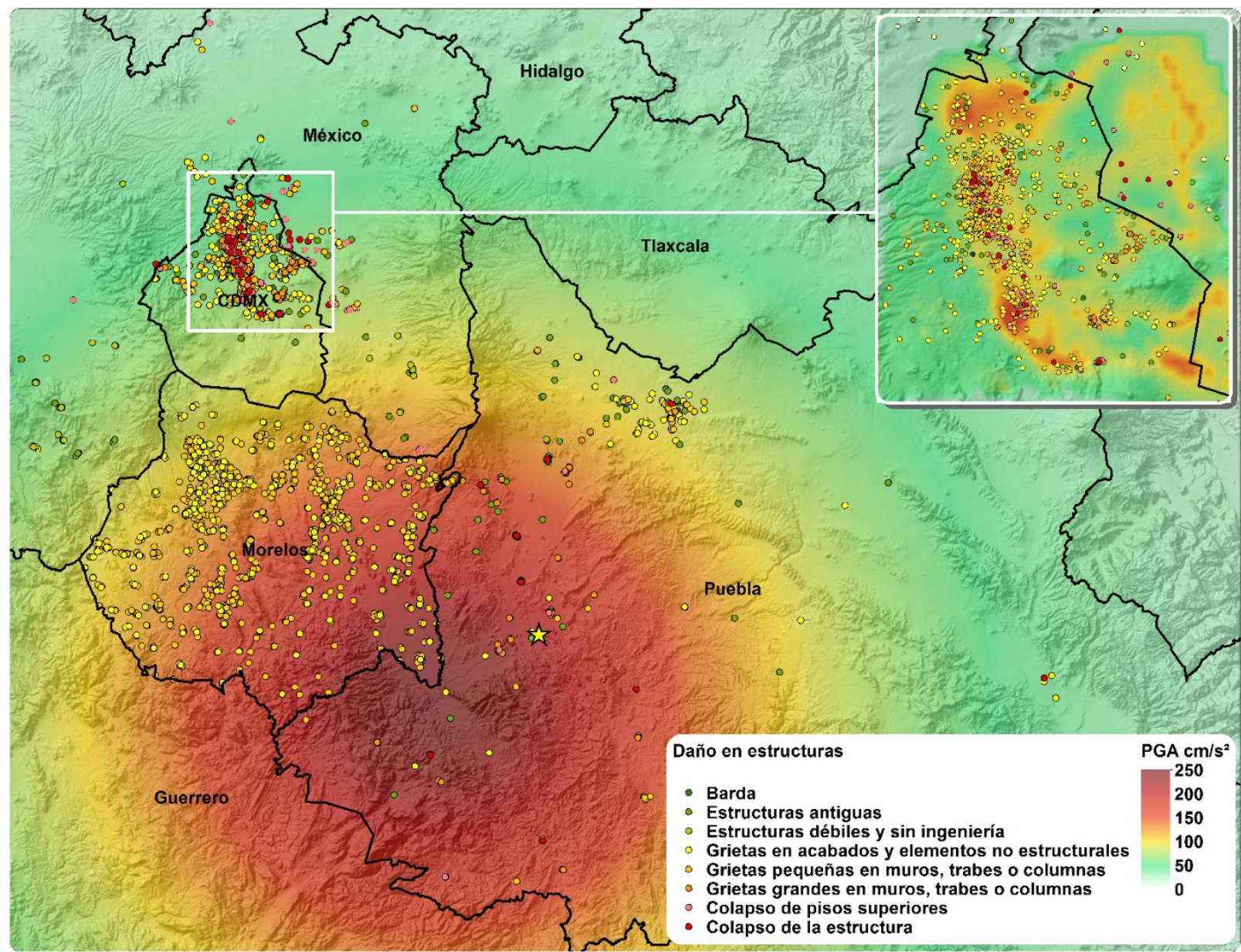

Figura 6. Mapa de intensidad (PGA) y de daños causados por el sismo del 19 de septiembre del 2017

Con base en la caracterización de daños que se presenta en la tabla 1, en combinación con los parámetros relacionados con el comportamiento estructural, tales como el tipo estructural, el uso de la edificación, el número de niveles, el año de construcción, entre algunas otras, se realizó una segregación en las bases de datos de daños, pudiendo así obtener estadísticas que relacionan estas dos características.

Se logró conformar una base de datos con 1677 registros repartidos de la siguiente manera: 1192 en la CDMX, 384 en el Estado de Puebla y 200 en el Estado de México. Analizando los daños de acuerdo a la caracterización propuesta en la tabla 1 se realizó la figura 7. Se puede observar que se registraron al menos 57 bardas que sufrieron daños durante este sismo, siendo el Estado de México con mayor número de casos. En estructuras antiguas se puede observar que al menos 213 edificaciones resultaron dañadas, como el caso del estado de Puebla donde existe un número considerable de iglesias y construcciones de la época colonial, lo que aunado a la intensidad del sismo ocasionó que de estos tres estados fuera el más afectado en este rubro. Por otro lado, al menos 126 de las estructuras catalogadas como débiles y sin ingeniería resultaron dañadas. De las estructuras con tipos constructivos modernos, se puede observar que al menos 61 estructuras colapsaron totalmente y 46 lo hicieron de manera parcial, siendo la CDMX la entidad con más casos; al menos 159 estructuras resultaron dañadas de gravedad siendo de nuevo la CDMX la que tiene más casos. En la figura 8, se pueden observar algunos ejemplos de los daños presentados. 


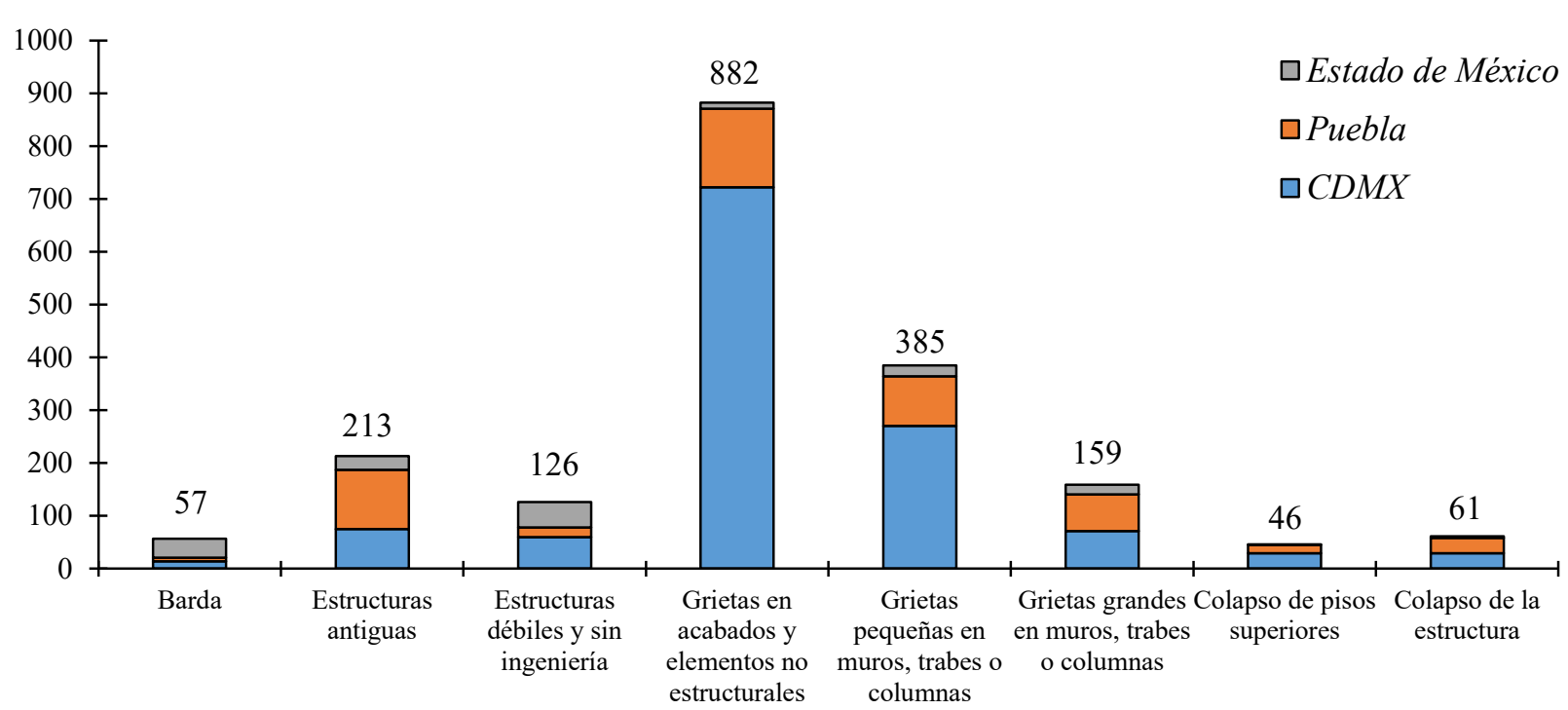

Figura 7. Número de estructuras dañadas por entidad acorde la caracterización de daño propuesta en la tabla 1

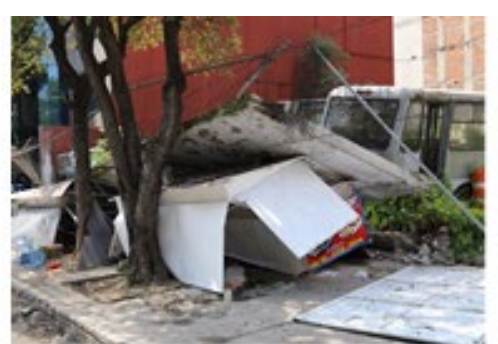

a)

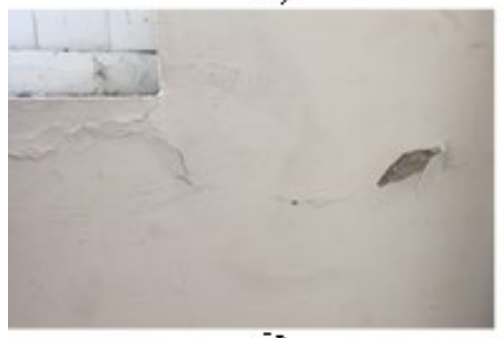

d)

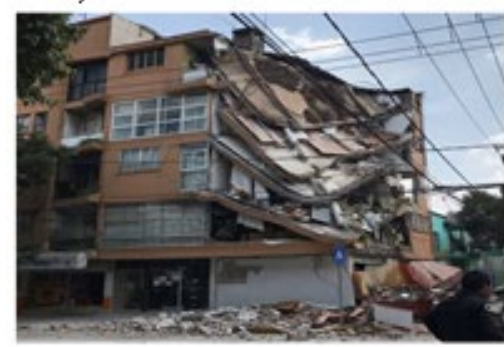

g)

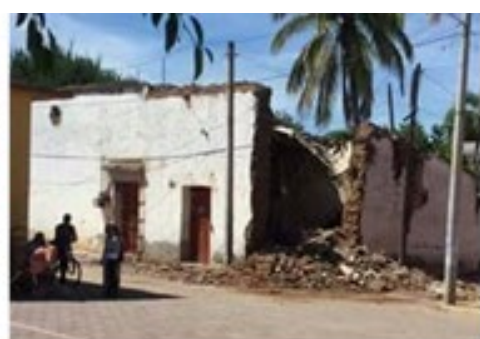

b)

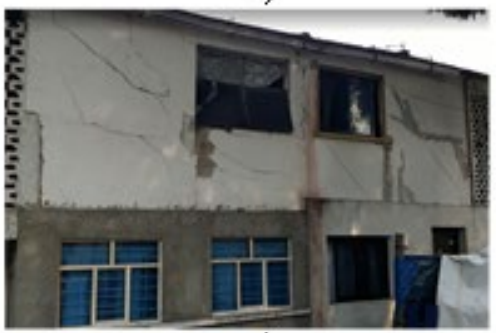

e)

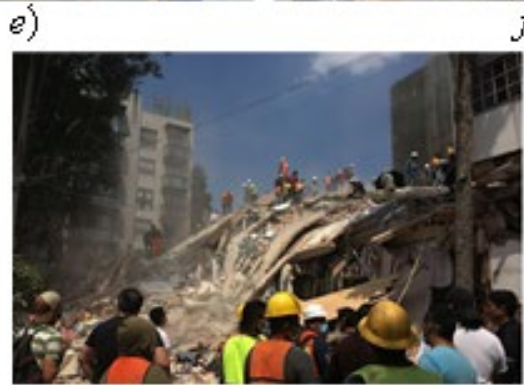

h)

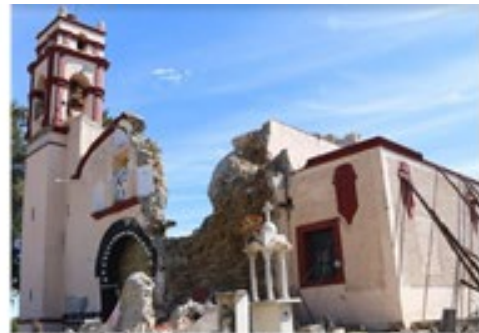

c)

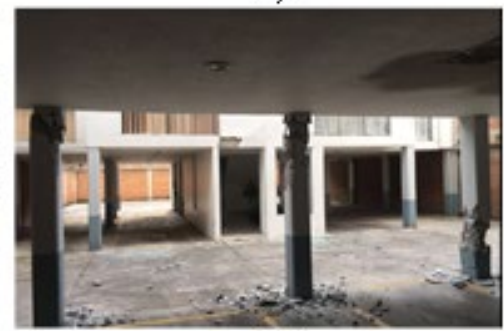

f)

Figura 8. Algunos ejemplos de estructuras dañadas en el sismo de septiembre de 2017 acorde a la tabla 1: $a$ ) daño en bardas, $b$ ) estructuras débiles y sin ingeniería, $c$ ) estructuras antiguas, $d$ ) grietas en acabados y elementos no estructurales, $e$ ) grietas pequeñas en muros, trabes o columnas, $f$ ) grietas importantes en muros, trabes o columnas, $g$ ) colapso de pisos superiores y $h$ ) colapso 
Atendiendo al uso de las estructuras, en la figura 9 podemos observar que el sector vivienda (casa habitación y edificios de departamentos) fue el más afectado, con al menos 1132 registros, lo que representa el 58 por ciento de todas las estructuras analizadas. Se puede observar que las casas habitación tienen un mayor número de estructuras con grietas grandes en elementos estructurales y colapsos totales, en relación con los demás usos considerados. También se observa que un gran número de las casas habitación que resultaron dañadas son estructuras débiles y sin ingeniería, las cuales resultan muy vulnerables ante las fuerzas sísmicas. Los edificios de departamentos presentan un mayor número de estructuras dañadas, sin embargo, la mayoría de estos son daños en acabados o daños leves en elementos estructurales.

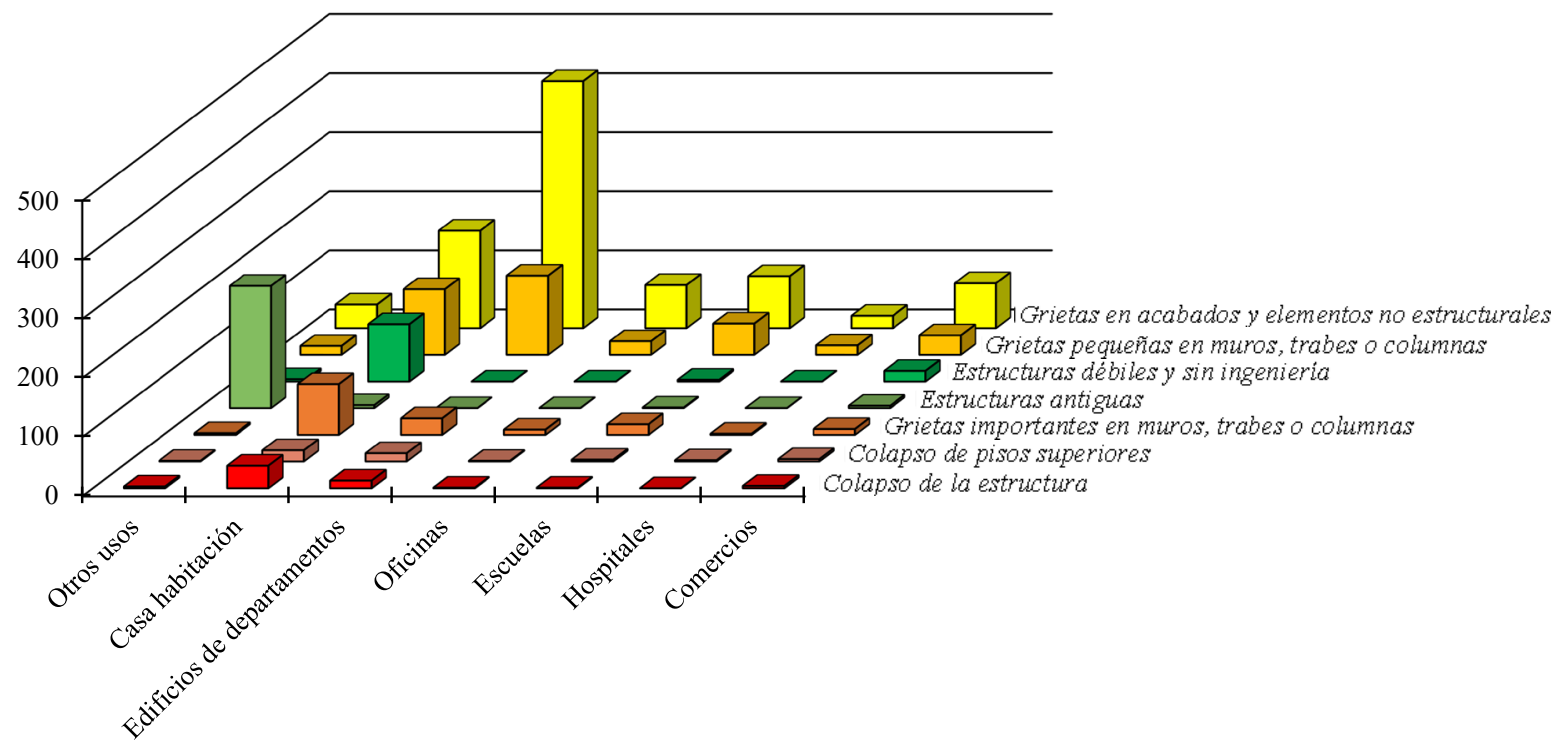

Figura 9. Número de estructuras dañadas de acuerdo al uso de la estructura y al estado de daño presentado

Para analizar los datos a partir del tipo estructural, se hizo la clasificación que se muestra en la tabla 2. La figura 10 muestra la distribución de daños por tipo estructural. Se muestra que hubo muchos daños en estructuras de muros de mampostería confinada (MCF), sin embargo, la mayoría no fueron graves; esto es porque la mayoría de las casas y edificios de vivienda construidos en México tienen este sistema estructural, y no significa que sea vulnerable, al contrario, es un sistema estructural muy resistente ante fuerzas sísmicas. A partir de los datos de los colapsos, se puede observar que las estructuras hechas a base de muros de mampostería no confinada (MNC), muy vulnerables ante fuerzas sísmicas, fueron las que resultaron con un mayor número de casos. Las estructuras hechas a base de losas planas (CLP), una vez más (desde el sismo de 1985 se ha observado esto), fueron las estructuras con peor desempeño en la CDMX, con 21 colapsos (parciales o totales).

Tabla 2. Tipos estructurales analizados

\begin{tabular}{cc}
\hline ID & Tipo estructural \\
\hline MC & Marcos de concreto \\
MCM & Marcos de concreto con muros de mampostería de relleno \\
MA & Marcos de acero \\
CLP & Columnas y losas planas de concreto \\
MAD & Muros de mampostería de adobe \\
MNC & Muros de mampostería no confinada \\
MCF & Muros de mampostería confinada \\
MMH & Muros de mampostería histórica \\
\hline
\end{tabular}




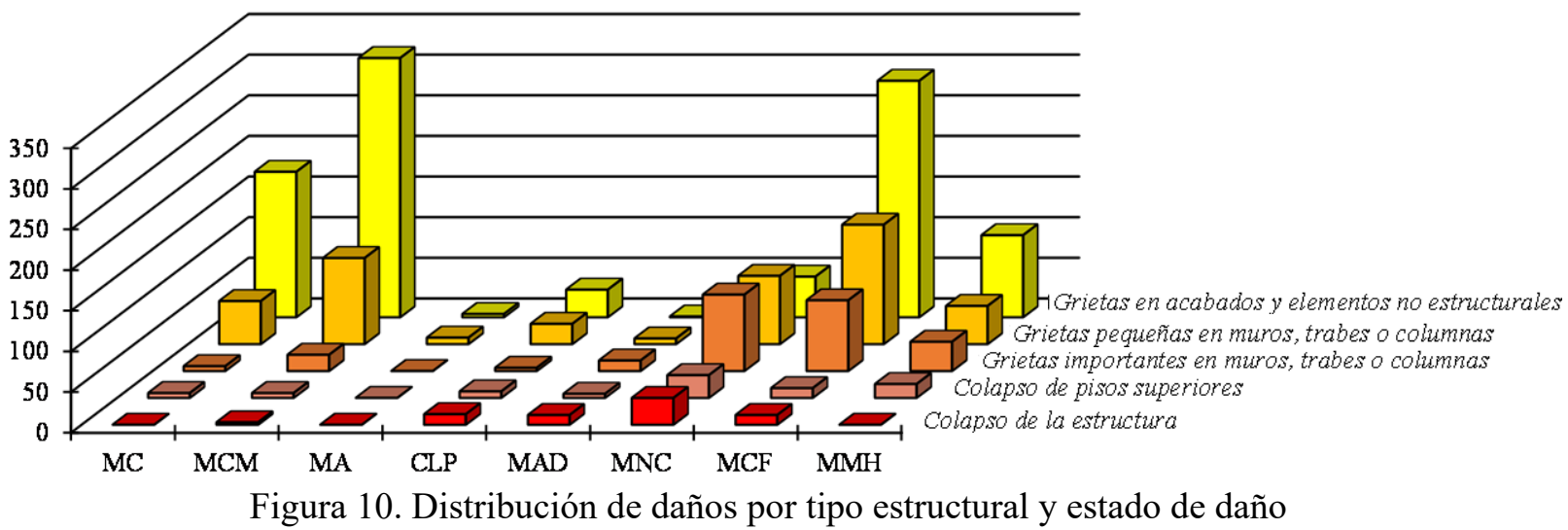

En la figura 11 se presenta la base de datos en función del número de pisos. Se observa que las estructuras con uno y dos niveles fueron las más afectadas, representando más del 45 por ciento. Esto se debe a que son las estructuras más abundantes, no a que sean más vulnerables. También se puede observar que, aunque la mayoría de los daños presentados fue en estructuras de dos niveles, estos en su mayoría no fueron graves. También se puede observar dentro de las estructuras dañadas de uno y dos niveles un alto número de estas pertenece a estructuras antiguas o sin ingeniería, lo que explica en parte los daños.

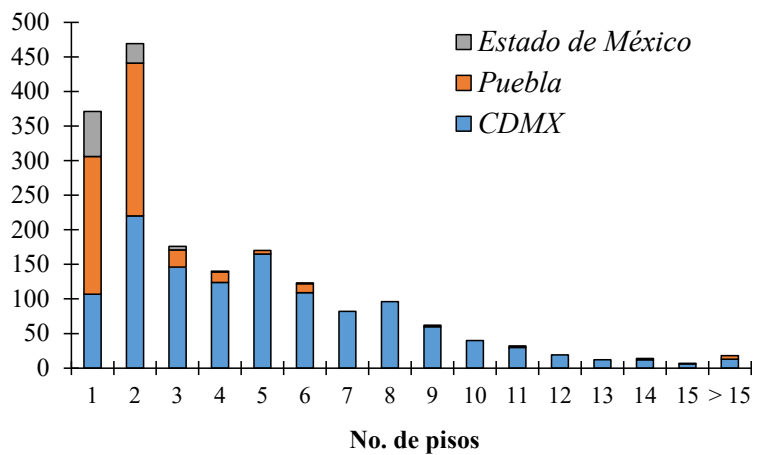

a)

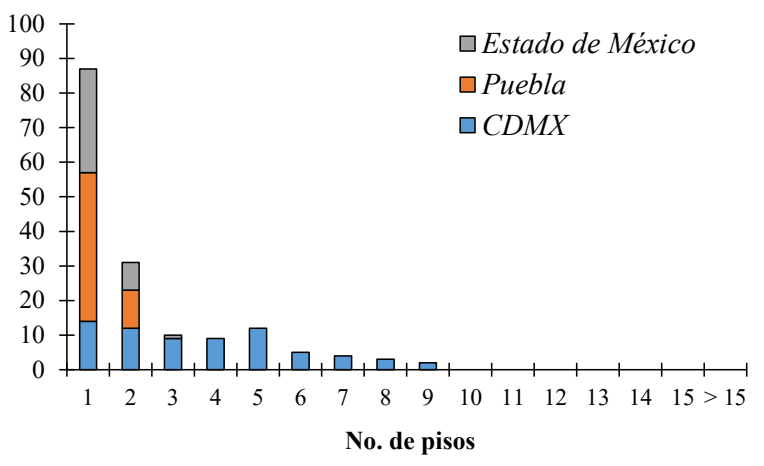

b)

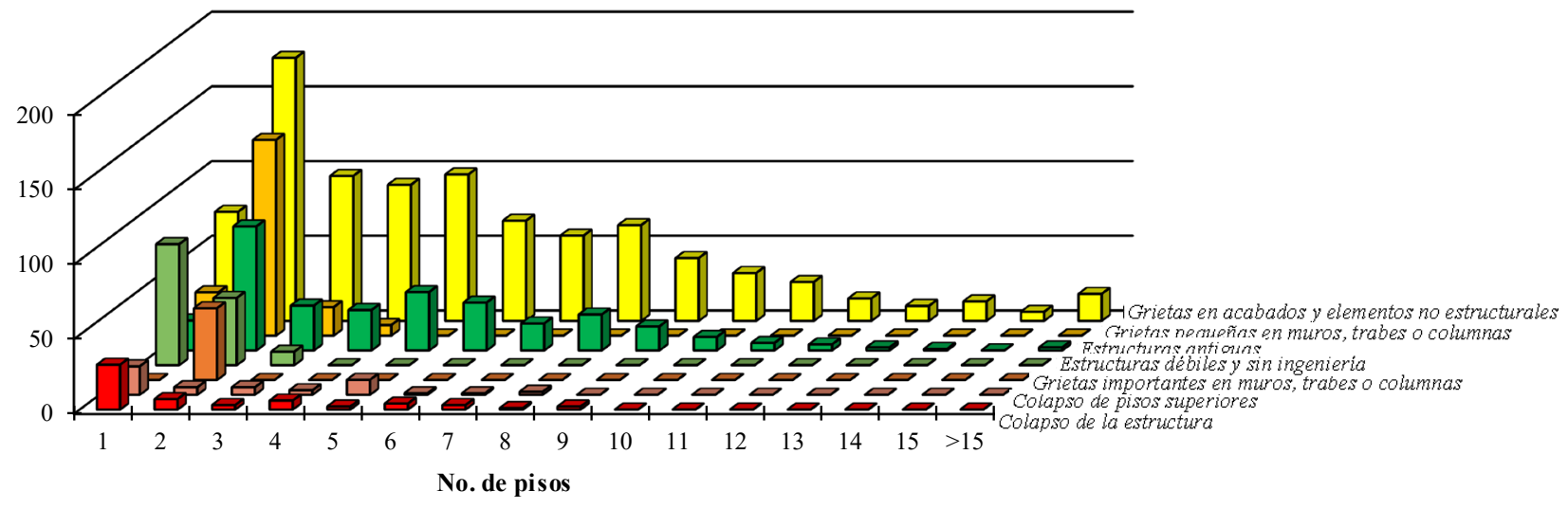

c)

Figura 11. Distribución de estructuras dañadas por número de niveles: $a$ ) toda la base de datos, $b$ ) colapsos parciales o totales y $c$ ) tipo de daño 
Otro aspecto que es crucial estudiar es el de los factores agravantes de daño, aquellos que modifican de manera negativa la respuesta de la estructura, provocando que ésta resulte más dañada de lo esperado. En la tabla 3 se presentan los factores agravantes considerados en este estudio.

Tabla 3. Factores agravantes de daño

\begin{tabular}{ccl}
\hline ID & Factor agravante & Efectos negativos adicionales a la demanda de aceleración \\
\hline Esq & Efecto de esquina & Demandas adicionales de torsión \\
I-plan & Irregularidad en planta & Demandas adicionales de torsión \\
I-ele & Irregularidad en elevación & Demandas adicionales de desplazamientos y resistencia \\
Golp & Golpeteo & Demandas adicionales de resistencia, daños adicionales \\
Pbd & Planta baja débil & Demandas adicionales de desplazamiento y resistencia \\
C-cor & Columnas cortas & Demandas adicionales de resistencia \\
E-ala & Edificio alargado & Demandas adicionales de torsión \\
D-pre & Daños previos & Degradación de resistencia \\
\hline
\end{tabular}

En la figura 12 se muestra la estadística de los daños considerando los agravantes de la tabla 3. En la misma figura se observa que la mayoría de las estructuras dañadas presentan irregularidad en planta (I-plan) o efecto de esquina (Esq), es decir, los efectos de torsión fueron importantes en los daños observados. Por otro lado, se puede observar que las estructuras con planta baja débil (Pbd) también resultaron con un alto número de estructuras dañadas. Por otro lado, el golpeteo (Golp) fue otro factor decisivo que contribuyó a que muchas estructuras colapsaran sobre todo en la CDMX. También se puede ver que la planta baja débil (Pbd), característica que lamentablemente se ha replicado mucho en edificios de departamentos y oficinas por la presencia de estacionamientos y comercios en la planta baja, fue otro factor que contribuyó a que muchas edificaciones sufrieran algún tipo de colapso.

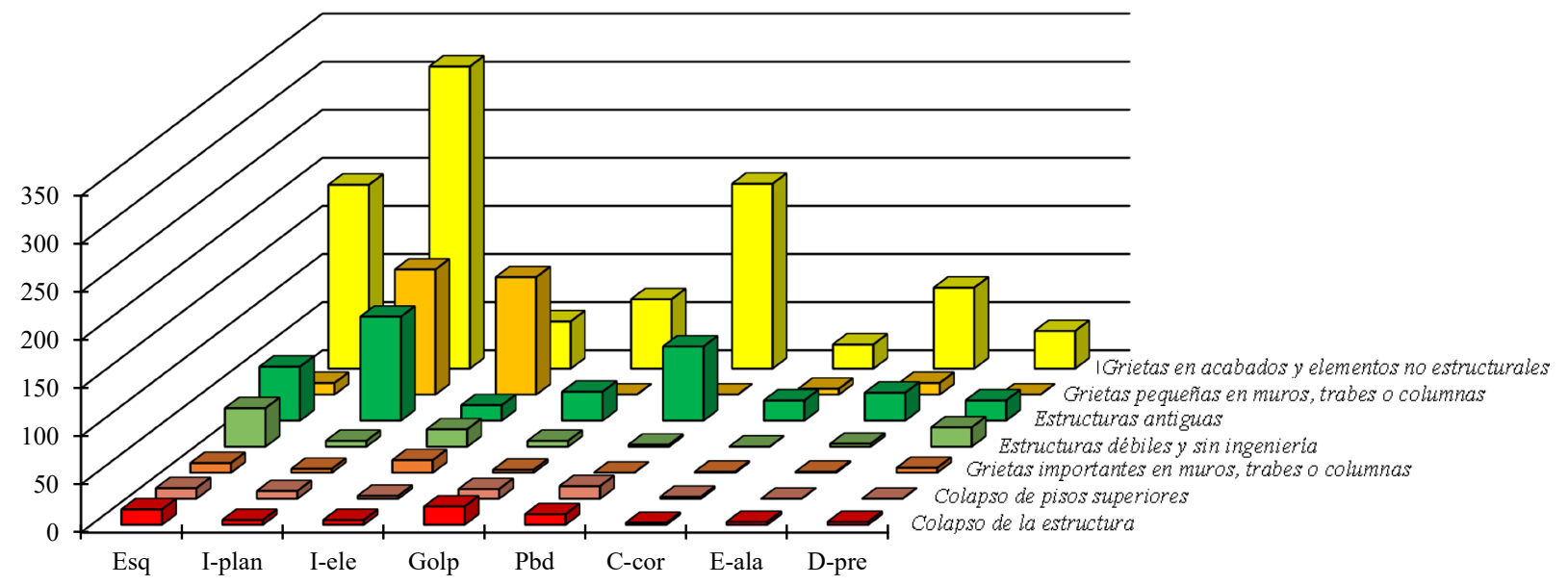

Figura 12. Distribución de estructuras dañadas según el agravante estructural observado

Para el caso de la CDMX fue posible realizar algunas estadísticas adicionales debido a información disponible que no lo está para otras entidades de la Republica, tales como el año de construcción de las estructuras y el reglamento de construcciones vigente, además de parámetros como el periodo de vibrar del suelo en las distintas zonas que la conforman.

La figura 13 muestra los datos en función de la década en que fueron construidos los edificios en la CDMX. Se puede observar que la mayoría de las estructuras dañadas fueron construidas entre las décadas de los años sesenta y noventas, sin embargo, restringiendo los daños a solo colapsos, es posible observar que las estructuras construidas entre 1970 y 1990 fueron las estructuras que registraron mayor número de colapsos. Durante estas décadas hubo un gran auge en la construcción de edificaciones a base de losas planas, dato que es congruente con el tipo estructural que registró más colapsos en la CDMX durante este 
sismo (figura 10). Existen al menos once estructuras construidas después del reglamento de 1987 que colapsaron total o parcialmente, lo que evidencia fallas graves en el diseño o construcción.

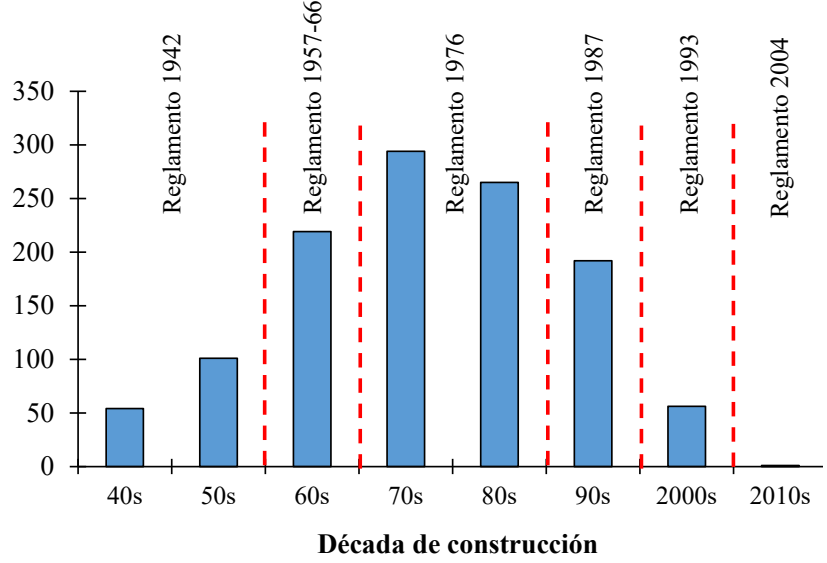

a)

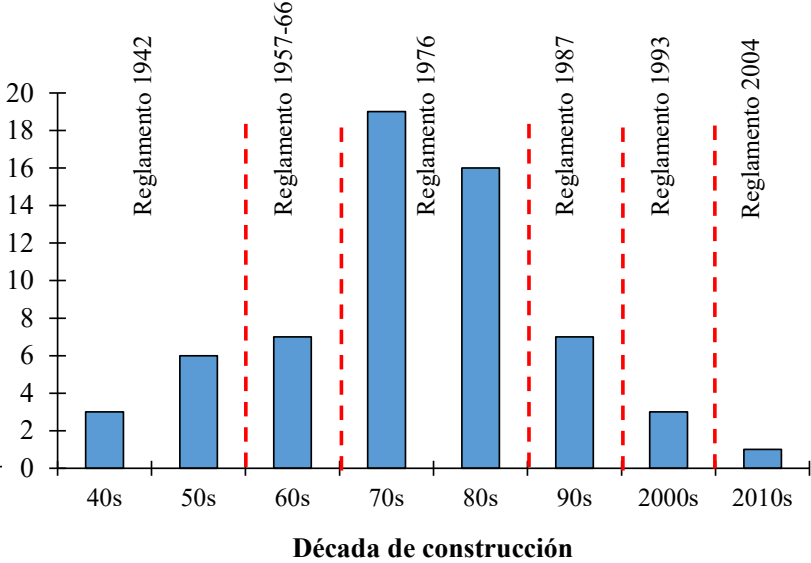

b)

Figura 13. Distribución de estructuras dañadas en la CDMX según el año de construcción y el reglamento de construcción vigente para: $a$ ) toda la base de datos, $b$ ) colapsos parciales o totales

La figura 14 muestra el periodo del suelo $\left(T_{s}\right)$, con intervalos de $0.5 \mathrm{~s}$, sobre el que está desplantada cada una de las estructuras dañadas en la CDMX. El 81 por ciento de las estructuras analizadas están en un intervalo de periodos 0.5 a 2.0 segundos, mientras que el 85 por ciento de las estructuras colapsadas se encontraba en esas zonas. Esto es un reflejo de que la intensidad del movimiento fue muy fuerte en estos intervalos, y de que la intensidad es la suma de las ondas propias de un sismo relativamente cercano de magnitud intermedia con la respuesta del suelo justamente con esos valores de periodos.

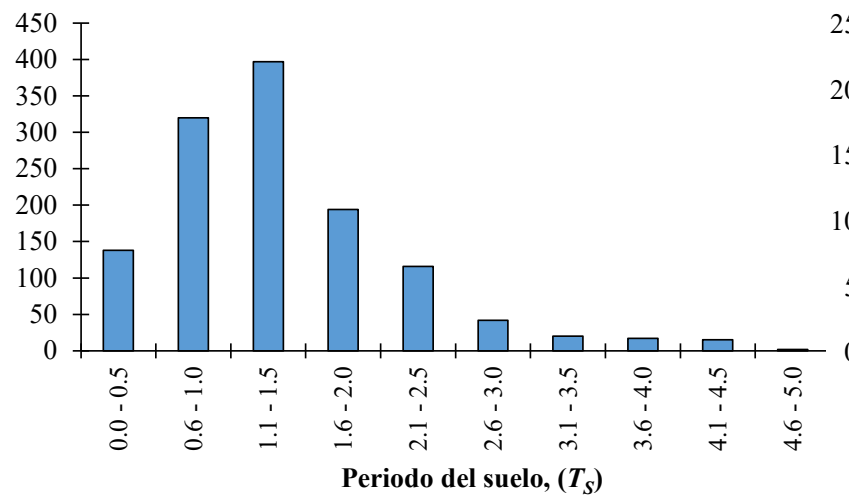

a)

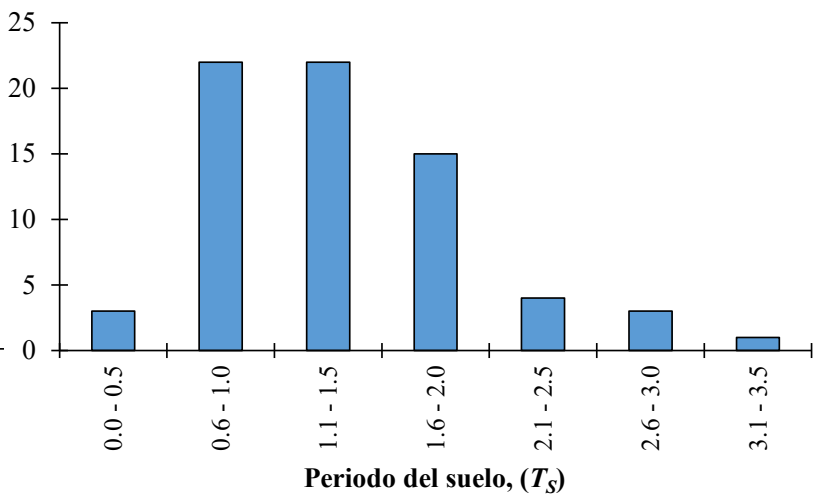

b)

Figura 14. Distribución de estructuras dañadas en la CDMX según el periodo del suelo para: $a$ ) toda la base de datos, $b$ ) colapsos parciales o totales

Mediante el uso de ecuaciones empíricas se estimó el periodo fundamental de vibración $\left(T_{e}\right)$ de las estructuras contenidas en la base de datos de acuerdo a su tipo estructural, tales como estructuras de mampostería (Muriá, 1995), marcos de concreto (Goel y Chopra, 1997), marcos de acero (Young y Adeli; 2014) y marcos de concreto con muros de relleno (Panagiotis A et al., 2015). Así se pudo obtener una relación entre el periodo del suelo y el periodo fundamental de la estructura. En la figura 15 se observa que el período $T_{e}$ de las estructuras que resultaron colapsadas (marcadores circulares) se encuentra por debajo del valor de $T_{s}$, esto indica que otras circunstancias tales como los factores agravantes pudieron haber adquirido una mayor relevancia en los daños observados. Es necesario aclarar que en este análisis, las 
ecuaciones empíricas utilizadas para la estimación de los periodos fundamentales de vibración de las estructuras analizadas corresponden a estructuras que permanecen en el rango elástico, es decir, estructuras que no han sufrido daño, no obstante, cuando las estructuras comienzan a dañarse (caso de las estructuras analizadas) su periodo de vibrar se degrada, haciéndolas más flexibles y en la mayoría de los casos, llevándolas a sufrir demandas de aceleración superiores.

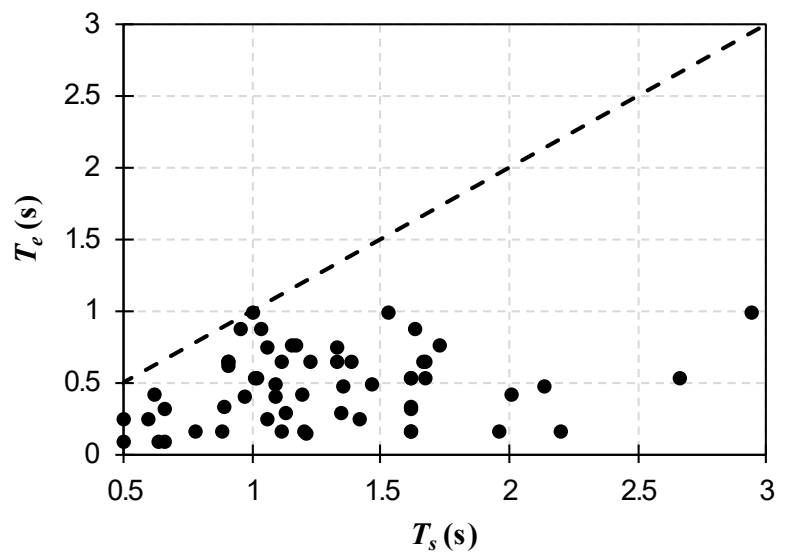

Figura 15. Estructuras colapsadas en la CDMX según la relación periodo elástico de la estructura $\left(T_{e}\right)$ y periodo del suelo $\left(T_{s}\right)$

Con la finalidad de conocer las diferencias entre las demandas que produjo el sismo sobre las estructuras colapsadas y las aceleraciones de diseño contempladas por el reglamento vigente durante la ocurrencia del sismo (Gobierno del Distrito Federal, 2004), se estimaron las demandas sísmicas sobre estas estructuras a través de mapas de aceleración espectral del IINGEN. Mientras, las aceleraciones de diseño se estimaron mediante el cálculo de las ordenadas espectrales correspondientes al periodo de fundamental de la estructura analizada según las ecuaciones proporcionadas en el Apéndice A de las Normas Técnicas Complementarias para Diseño por Sismo 2004 (NTC-S 2004) (Gobierno del Distrito Federal, 2004); dichas ordenadas espectrales corresponden al espectro elástico sin reducción por sobrerresistencia. En la figura 16 se observa que las demandas sísmicas que sufrieron todas las estructuras colapsadas, se encuentran por debajo de los valores de aceleración de diseño que proponían las NTC-S 2004 (Gobierno del Distrito Federal, 2004); por lo tanto, se podría concluir, que todas las fallas observadas fueron causadas por un mal diseño o una mala ejecución.

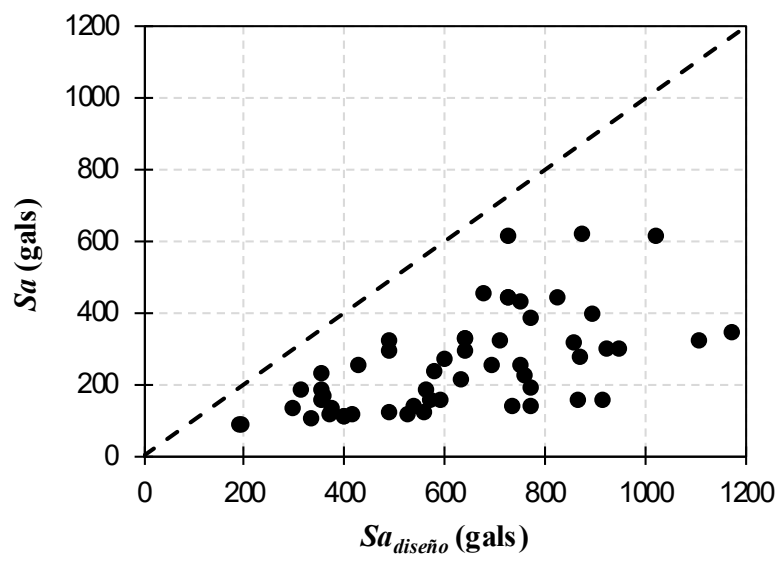

Figura 16. Estructuras colapsadas en la CDMX según la relación de la aceleración espectral en el sitio de la estructura contra la aceleración de diseño indicada por las NTC-S 2004 


\section{CONCLUSIONES}

El sismo del 19 de septiembre de 2017 fue uno de los más catastróficos en la historia moderna de México, dado que muchas estructuras resultaron dañadas y colapsadas. Analizando datos de diversas fuentes fue posible conformar bases de datos con el fin de realizar diversos análisis estadísticos que permitieron concluir lo siguiente:

1. En todos los casos, las edificaciones destinadas a viviendas fueron las más afectadas. En la CDMX más del 75 por ciento de los edificios analizados estaban destinados a este uso. De este porcentaje, el 66 por ciento son edificios de departamentos y el 34 por ciento casas habitación. Para el caso de otros estados al menos, el 33 por ciento de la muestra analizada fueron casas habitación.

2. Este sismo afectó principalmente a las edificaciones de baja a mediana altura. Se pudo observar que para la CDMX los edificios de entre 1 y 10 niveles fueron los más afectados, mientras que para otros estados fueron los edificios entre 1 y 2 niveles, coincidiendo con la altura típica de edificaciones en las zonas afectadas.

3. Los tipos estructurales que resultaron con daños, son los que están compuestos con muros, debido a la poca ductilidad con la que cuentan estas estructuras. Sin embargo, se pudo observar que, desde el punto de vista de los colapsos, estructuras construidas con losas planas en la CDMX y estructuras de mampostería sin confinar, fueron las más afectadas.

4. En cuanto a los factores agravantes de daño, se pudo observar que los efectos de torsión causados por efectos de esquina e irregularidades geométricas contribuyeron mucho en los daños observados, por otro lado, efectos como el golpeteo y la planta baja débil fueron factores adicionales que contribuyeron de igual manera a que muchas estructuras colapsaran.

5. Se pudo observar que para el caso de la CDMX la mayoría de las estructuras dañadas fueron construidas entre los años 60's y 80's, siendo las de los años 70's las que presentaron un mayor número de estructuras dañadas. Se pudo observar además que existieron algunos casos en que las estructuras fueron construidas después del sismo de 1985, y aun así resultaron dañadas lo que podría indicar errores durante su diseño y/o construcción.

6. Para el caso de la CDMX, se observó que los efectos de resonancia sobre las estructuras colapsadas no fue un factor determinante en los daños observados, ya que las relaciones entre el periodo de la estructura y el suelo resultan menores que la unidad. Además, existen en la zona de daños miles de estructuras similares a las dañadas que no sufrieron daño, por lo que las fallas no pueden ser atribuidas a la resonancia.

7. Comparando las demandas de aceleración que el sismo produjo en las estructuras colapsadas con las aceleraciones de diseño proporcionadas en el reglamento vigente, se pudo observar que, en todos los casos, las demandas estuvieron por debajo de las aceleraciones de diseño, lo que también permite concluir que estas estructuras pudieron haber tenido un mal diseño o una mala ejecución de la obra, lo que ocasionó que estas estructuras fallaran.

\section{AGRADECIMIENTOS}

Se agradece a los ingenieros, Faustino Ventura, Edgar Ozuna y Diego Felipe Gudiño por su ayuda en la creación de mapas y el manejo de los sistemas de información geográfica. De la misma manera se agradece al Dr. Marco Torres, a los becarios Jony Zenón Martínez, Agustín Sánchez Moreno, Jose Eduardo García, Lizbeth Moreno y Luis Enrique Cortés por el apoyo en la recolección de información para la creación de la base de datos utilizada en este estudio. 


\section{REFERENCIAS}

CICM-SMIE (2017). “Sismos México. Mapas”: https://www.sismosmexico.org/mapas

Díaz, A, P Murren y S Walker (2017), “32 years after Michoacán: Preliminary reconnaissance observations in the aftermath of the September 19, 2017 Puebla - Morelos Earthquake", Skidmore, Owings and Merrill, LLP., http://learningfromearthquakes.org

EERI (2017), "Webinar recording: Mexico earthquake reconnaissance briefing”, http://learningfromearthquakes.org

EERI (2018), "Webinar recording: Case studies from September 19, 2017 Mexico Earthquake", http://learningfromearthquakes.org

ERN (2018), "Visualizador de daños CDMX”, http://serv.ern.com.mx:8081

Galvis, F, E Miranda, P Heresi, H Dávalos y J R Silos (2017), "Preliminary statistics of collapsed buildings in Mexico City in the September 19, 2017 Puebla-Morelos Earthquake", John A. Blume Earthquake Engineering Center and Department of Civil and Environmental Engineering Stanford University, http://learningfromearthquakes.org

GEER (2017), "Geotechnical Engineering reconnaissance of the September $2017 \mathrm{Mw} 7.1$ Puebla-Mexico City Earthquake", Reporte No. GEER 055A, Geotechnical Extreme Events Reconnaissance Association, Septiembre de 2017, DOI: DOI : 10.18118/G6JD46

Gobierno del Distrito Federal (1976), "Reglamento de Construcciones para el Distrito Federal”, Diario Oficial de la Federación, Distrito Federal, México

Gobierno del Distrito Federal (1987), "Normas Técnicas Complementarias al RCDF”, Diario Oficial de la Federación, Distrito Federal. México

Gobierno del Distrito Federal (2004), "Normas Técnicas Complementarias para Diseño por Sismo”, Diario Oficial de la Federación, Distrito Federal, México

Gobierno de la Ciudad de México (2017) "Plataforma CDMX, Comisión para la reconstrucción”, https://plataforma.cdmx.gob.mx/

Goel, R y A Chopra (1997), "Period Formulas for Moment-Resisting Frame Buildings", Journal of Structural Engineering, Vol. 129, No. 11, pp. 1454-1461. DOI: 10.1061/(ASCE)07339445(1997)123:11(1454)

Google (2017). "Mapa preliminar de daños en la Ciudad de México", http://google.org/crisismap/a/gmail.com/v19s

Muriá D y R González (1995), "Propiedades dinámicas de edificios de la Ciudad de México", Revista de Ingeniería Sísmica. SMIS, No. 51, pp. 24-45. DOI: 10.18867/ris.51.261

NOTIMEX (2017), "Segob actualiza cifra de muertos por sismo del 19-S; suman 369”, Excélsior, www.excelsior.com.mx

Orozco, V y E Reinoso (2007), "Revisión a 50 años de los daños ocasionados en la Ciudad de México por el sismo del 28 de julio de 1957 con ayuda de investigaciones recientes y sistemas de información geográfica", Revista de Ingeniería Sísmica, SMIS, No. 76, pp. 61-87. DOI: 10.18867/ris.76.131

Ordaz, M, F Martinelli, A Aguilar, J Arboleda, C Meletti y V D’Amico (2017) R-CRISIS. Programa y plataforma para calcular amenaza sísmica. 
Análisis de los daños en viviendas y edificios comerciales durante la ocurrencia del sismo del 19 de septiembre de 2017

Panagiotis, G, C Constantinos, C Liborio, S Vasilis y A Adamantia (2015), "On the fundamental period of infilled RC frame buildings”, Structural Engineering and Mechanics. Vol. 54, No. 6, pp 1175-1200. DOI: $10.12989 / \mathrm{sem} .2015 .54 .6 .1175$

Rodriguez-Nikl, T (2017), "Preliminary report on damage caused in Mexico City by September 13, PueblaMorelos, Mw 7.1 Earthquake, documented from October 14 to 17, 2017". Reporte EBRS001 / RSIC001, https://zenodo.org/record/1039321

Verificado 19S (2017). “Capas de información”, http://www.verificado19s.org/

Young K, y H Adeli (2014), "Fundamental period of irregular moment-resisting steel frame structures", The structural design of tall and special buildings, No. 23, pp. 1141-1157. DOI: 10.1002/tal.1112 